\title{
Resumption of JRR-4 and characteristics of neutron beam for BNCT
}

\author{
T. Nakamura ${ }^{\mathrm{a}, *}$, H. Horiguchi ${ }^{\mathrm{a}}$, T. Kishi ${ }^{\mathrm{a}}$, J. Motohashi ${ }^{\mathrm{a}}$, F. Sasajima ${ }^{\mathrm{a}}$ and H.Kumada ${ }^{\mathrm{b}}$ \\ ${ }^{a}$ Department of Research Reactor and Tandem Accelerator, Japan Atomic Energy Agency, Tokai, \\ Ibaraki, Japan \\ ${ }^{b}$ A Graduate school of Comprehensive Human Sciences, University of Tsukuba, 1-1-1 Tennodai, \\ Tsukuba, Ibaraki, Japan
}

\begin{abstract}
The clinical trials of Boron Neutron Capture Therapy (BNCT) have been conducted using Japan Research Reactor No.4 (JRR-4) in Japan Atomic Energy Agency (JAEA). In December 28th, 2007, the crack of a graphite reflector in the reactor core was found on the weld of the aluminum cladding. For this reason, specifications of graphite reflectors were renewed; dimensions of the graphite were reduced and gaps of the water were increased. All existing graphite reflectors of JRR-4 were changed by new graphite reflectors. In February, 2010, the resumption of JRR-4 was carried out with new graphite reflectors. We measured the characteristics of neutron beam at the JRR-4 Neutron Beam Facility. A cylindrical water phantom of $18.6 \mathrm{~cm}$ diameter and $24 \mathrm{~cm}$ depth was set in front of the beam port with $1 \mathrm{~cm}$ gap. TLDs and gold wires were inserted within the phantom when the phantom was irradiated. The results of the measured thermal neutron flux and the gamma dose in water were compared with that of MCNP calculation.The neutron energy spectrum of calculation model with new reflector had little variation compared to that with old reflector. But, intensities of the neutron flux and gamma dose with new reflector were rather smaller than those with old reflector. The calculated results showed the same tendency with the experimental results. Therefore, the clinical trials of BNCT in JRR-4 could be restarted.
\end{abstract}

Keywords: BNCT, JRR-4, MCNP, Au wire, Neutron flux, Reaction rate

\section{Introduction}

The clinical trials for boron neutron capture therapy (BNCT) by using the neutron beam facility installed in Japan Research Reactor No.4 (JRR-4) in Japan Atomic Energy Agency (JAEA) have been conducted since 1999. In December 28th, 2007, the crack of a graphite reflector in the reactor core was found on the weld of the aluminum cladding (Horiguchi et al., 2009). For this reason, the specifications of the graphite reflectors were renewed (see Figure 1); the volume of graphite reflectors were reduced (thickness: $57 \mathrm{~mm}$ (New), $66 \mathrm{~mm}$ (Old)) and the gap of water in the direction toward the irradiation room were increased to about 6.5mm. In February, 2010, the resumption of JRR-4 was carried out with new graphite reflectors.

To evaluate the influence of neutron beams by new reflectors with the specifications change, we performed calculations of the core model by MCNP5 code (X-5 Monte Carlo Team, 2003). From the calculation results, it was found that the characteristics of neutron beams of BNCT irradiation affect the water gap and the graphite reflectors. Hence, experimental measurements were necessary before any restart of BNCT in JRR-4. Experimental measurements of thermal neutron flux and gamma dose in the cylindrical water phantom were performed. The ratios (C/E) of calculated and experimental values were evaluated, and neutron spectra computed by means of 
MCNP code.

\section{Materials and Methods 2.1 Medical Irradiation Facility at JRR-4}

The neutron beam facility (see Figure 2) at JRR-4 was designed to be capable of providing both thermal and epithermal neutron beams. The thermal neutron beam was used continuously for the Japanese BNCT trials as intra-operative irradiation. The epithermal neutron beam has been used for deep-seated cancer and without craniotomy during irradiation. The heavy water tank has four layers of different thicknesses such as $16 \mathrm{~cm}, 4 \mathrm{~cm}, 8 \mathrm{~cm}$, and $5 \mathrm{~cm}$. The heavy water can be discharged separately by pressurized helium gas. For the specific medical irradiation, we use three neutron beam modes, which are called Thermal Neutron Beam Mode I (TNB-1), Thermal Neutron Beam Mode II (TNB-2) and Epithermal Neutron Beam Mode (ENB) (Yamamoto et al., 2000). The characteristics of these beams are shown in Table 1. In addition, the monitor holders mounted near the bismuth block set three gold wire monitors.

\subsection{Reaction rate}

The intensity of the epithermal neutron beam can be calibrated using the gold standard. The gold wire with $0.25 \mathrm{~mm}$ outer diameter and $25 \mathrm{~mm}$ length is inserted into a cadmium tube that is $2 \mathrm{~mm}$ outer diameter, $1 \mathrm{~mm}$ inner diameter and $30 \mathrm{~mm}$ length, with both ends closed. This detector is called a gold wire monitor in this report. The reaction rate $R R$ of the monitors is defined as following:

$$
R R=\sigma \phi
$$

where, $\sigma$ is cross section (barn), $\phi$ is neutron flux $\left(\mathrm{n} / \mathrm{cm}^{2} / \mathrm{s}\right)$.

\subsection{Calibration}

Two scaling factors, namely the reactor power scaling factor and the calculation/experiment $(\mathrm{C} / \mathrm{E})$ scaling factor, are necessary in order to correct with the calculation and actual irradiation experiment. In experiments, a cylindrical water phantom of $18.6 \mathrm{~cm}$ diameter and $24 \mathrm{~cm}$ depth was set in front of the beam port with $1 \mathrm{~cm}$ gap; thermal neutron flux in the phantom and the reaction rate of the gold wire monitors were measured. In particular, the thermal neutron flux in the phantom also was measured by using the gold wire monitor put on a central axis of the phantom. The activities of the gold wires, which were cut in the $5 \mathrm{~mm}$ interval, were counted using the JRR-4 beta-gamma coincidence device. The reactor power calibration factor was obtained from the experiments based on the linearity of the reaction rate by gold monitors with the reactor power.

$\left(\phi_{\max }\right)_{\exp }=a \cdot R R$

where ( $\left.\phi_{\max }\right)_{\exp }$ is the maximum thermal neutron flux in the phantom, $a$ is a linear coefficient, $R R$ is the reaction rate of a gold wire monitor in the same experiment. The linear coefficient of reactor power is obtained by using the least squares method results from the several experiments at $1 \mathrm{MW}$, $2 \mathrm{MW}$ and 3.5MW. The reaction rate $R R_{0}$ of ENB obtained on February 23rd, 2010, was fixed as standard irradiation with $3.5 \mathrm{MW}$ operation. The reactor power calibration factor $f_{P}$ is defined as the ratio between $R R$ and the standard reaction rate: 
$f_{P}=\left(R R / R R_{0}\right)$

The C/E scaling factor, $f_{C / E}$, is a correction factor that accounts for differences between MCNP-5 radiation source and material descriptions adopted in the simulation and the real phantom experiments. It is defined as the ratio of the simulated and measured maximum thermal neutron flux in the phantom as follows:

$$
f_{C / E}=\frac{\left(\phi_{\max }\right)_{s i m}}{\left(\phi_{\max }\right)_{\exp 0}}=\frac{\left(\phi_{\max }\right)_{s i m}}{a \cdot R R_{0}}
$$

where $\left(\phi_{\max }\right)_{\operatorname{sim}}$ denote the simulated maximum thermal neutron flux in the phantom and ( $\phi$ $\left.{ }_{\max }\right)_{\exp 0}$ the measured maximum thermal neutron flux for the standard irradiation experiment under the same condition.

\section{Results and Discussion}

Figure 3 shows the thermal neutron flux distribution along the central axis in the phantom. Maximum values in this figure indicate the maximum thermal neutron flux used in the calibration. The linear coefficient $a$ in the equation 2 obtained by using the least squares method was $1.33 \times 10^{-2}\left(\mathrm{barn}^{-1}\right)$. We estimated the nuclear fission in reactor core from the saturation of the reactor thermal power, resulting in a reaction rate $R R_{0}$ of $2.16 \times 10^{11}\left(\mathrm{barn} \cdot \mathrm{n} / \mathrm{cm}^{2} / \mathrm{s}\right)$ at $3.5 \mathrm{MW}$ (ENB) on February 23rd, 2010.

As shown in Table 2, C/E scaling factors of the thermal neutron flux for ENB and TNB-1 beam modes are 1.011 and 0.994 (see Figure 3), respectively, according to the reactor thermal power standard irradiation modes. For the photon component of ENB, TNB-1 and TNB-2 beam modes, C/E scaling factors are 0.991, 0.959 and 0.963 (see Figure 4), respectively. Figure 5a shows free-in-air neutron spectra for the old and new reflectors of ENB, TNB-1 and TNB-2 modes at the aperture of the collimator. We found that the new graphite reflector has little effect, compared to the old reflector, on the obtained neutron spectrum. MCNP5 calculation model including the new graphite reflectors and updated cross section libraries for materials in the model agreed rather well with the experimental results.

The neutron beam intensity with the new graphite reflectors was estimated by experimental data.The nuclear fission in reactor core based on the reactor thermal power was used for normalization. At 3.5MW reactor thermal power, $R R_{0}$ is $2.33 \times 10^{11}$ for the old graphite reflectors and $2.16 \times 10^{11}$ for the new graphite set up. Thus, the neutron beam intensity decreased by approximately $8 \%$. Figure 5b shows calculated free-in-air neutron spectra ratio (New reflector / Old Reflector Ratio) for ENB, TNB-1 and TNB-2 modes at the aperture of the collimator. Therefore, we found that the neutron flux from $0.01 \mathrm{ev}$ to $10 \mathrm{keV}$ for the new graphite reflector is rather smaller than that of the old reflector. The neutron flux for 3 neutron energy group (thermal, epithermal and fast neutron) calculated by MCNP with the new graphite reflector were decreased relatively in approximately $8 \%$.

The clinical trials of BNCT in JRR-4 were restarted thanks to the obtained experimental results.

\section{Conclusions}

We measured the characteristics of neutron beam at the JRR-4 Neutron Beam Facility. It was found that the new graphite reflector has little effect, compared to the old reflector, on the neutron spectrum. In addition, the derived neutron flux from $0.01 \mathrm{eV}$ to $10 \mathrm{keV}$ for the new graphite reflector is rather smaller than that of the old reflector. The neutron flux for 3 neutron energy 
groups (thermal, epithermal and fast neutron) calculated by MCNP with new graphite reflector were decreased relatively in approximately $8 \%$.

\section{References}

Horiguchi, H., et al., 2009. Irradiation Growth of Graphite in Reflector Elements of JRR-4, RRFM2009.

X-5 Monte Carlo Team, 2003.MCNP-A General Monte Carlo N-Particle Transport Code, Version5.LA-UR-03-1987.

Yamamoto, K., et al., 2000. Characteristics of neutron beams at JRR-4 for BNCT, ICNCT-9, 243-244. 
Figure 1 Horizontal sectional view of the new core with the new graphite reflectors

Figure 2 Vertical sectional view of the JRR-4 Neutron Beam Facility

Figure 3 Thermal neutron flux distribution in the phantom in the ENB and TNB-1 modes

Figure 4 Gamma dose rate distribution in the phantom in the ENB, TNB-1 and TNB-2 modes

Figure 5 (a) Calculated neutron spectra by free air condition at aperture of collimator.(b) Ratio of new reflector/old reflector of calculated neutron spectra.

Table 1 Condition of the three beam modes with the JRR-4 Neutron Beam Facility

\begin{tabular}{cccc}
\hline Beam mode & $\begin{array}{c}\text { Thermal Neutron } \\
\text { Beam Mode }\end{array}$ & $\begin{array}{c}\text { Thermal Neutron } \\
\text { Beam Mode II }\end{array}$ & $\begin{array}{c}\text { Epithrmal Neutron } \\
\text { Beam Mode }\end{array}$ \\
\hline Beam & Mixed & Pure thermal & Epithermal \\
\hline Heavy Water Thickness & $12 \mathrm{~cm}$ & $33 \mathrm{~cm}$ & $8 \mathrm{~cm}$ \\
Cadmium Shutter & Off & Off & On \\
Bismuth Blocks & $18 \mathrm{~cm}$ & $18 \mathrm{~cm}$ & $18 \mathrm{~cm}$ \\
Graphite Bloks & $7 \mathrm{~cm}$ & $7 \mathrm{~cm}$ & $7 \mathrm{~cm}$ \\
Collimator Size & & Diameter $10 \mathrm{~cm}, 12 \mathrm{~cm}, 15 \mathrm{~cm}$ & \\
\hline
\end{tabular}

Table 2 C/E Scaling Factor according to Reactor Thermal Power

\begin{tabular}{|c|c|c|c|c|c|c|c|c|}
\hline Particle & $\begin{array}{l}\text { Beam } \\
\text { Mode }\end{array}$ & $\begin{array}{c}\text { Reactor } \\
\text { Thermal } \\
\text { Power }(\mathrm{kW})\end{array}$ & $\begin{array}{c}\text { Exp. RR } \\
\left(\text { barn·n/ } \mathrm{cm}^{2} / \mathrm{sec}\right)\end{array}$ & $\begin{array}{c}\text { Exp. } \\
\Phi_{\text {th_max }} \\
\left(\mathrm{n} / \mathrm{cm}^{2} / \mathrm{sec}\right) \\
\end{array}$ & $\begin{array}{c}\text { Exp. } \\
\gamma \text { Dose }_{\text {max }} \\
(\mathrm{mGy} / \mathrm{h})\end{array}$ & $\begin{array}{c}\text { Cal. } \\
\Phi_{\text {th_max }} \\
\left(\mathrm{n} / \mathrm{cm}^{2} / \mathrm{sec}\right)\end{array}$ & $\begin{array}{c}\text { Cal. } \\
\gamma \text { Dose }_{-m a x} \\
(\mathrm{mGy} / \mathrm{h})\end{array}$ & $\begin{array}{l}\mathrm{C} / \mathrm{E} \\
\text { Ratio }\end{array}$ \\
\hline \multirow{2}{*}{ Neutron } & $\mathrm{ENB}^{\mathrm{a}}$ & 3000 & $1.837 \times 10^{11}$ & $2.467 \times 10^{9}$ & & $2.493 \times 10^{9}$ & & 1.011 \\
\hline & TNB-1 $^{\mathrm{b}}$ & 3050 & $8.833 \times 10^{10}$ & $4.242 \times 10^{9}$ & & $4.216 \times 10^{9}$ & & 0.994 \\
\hline \multirow{3}{*}{ Photon } & $\mathrm{ENB}^{\mathrm{a}}$ & 174 & $1.075 \times 10^{10}$ & & 339 & & 337 & 0.991 \\
\hline & $\mathrm{TNB}^{\mathrm{b}} \mathrm{b}^{\mathrm{b}}$ & 176 & $5.102 \times 10^{9}$ & & 488 & & 468 & 0.959 \\
\hline & TNB- $^{\mathrm{c}}$ & 194 & $9.002 \times 10^{9}$ & & 113 & & 109 & 0.963 \\
\hline
\end{tabular}

a. The reaction rate $\mathrm{RR}_{0}$ obtained on February 23rd, 2010 was fixed as standard irradiation.

b. The reaction rate $\mathrm{RR}_{0}$ obtained on April 28th, 2010 was fixed as standard irradiation.

c. The reaction rate $\mathrm{RR}_{0}$ obtained on March 29th, 2010 was fixed as standard irradiation. 


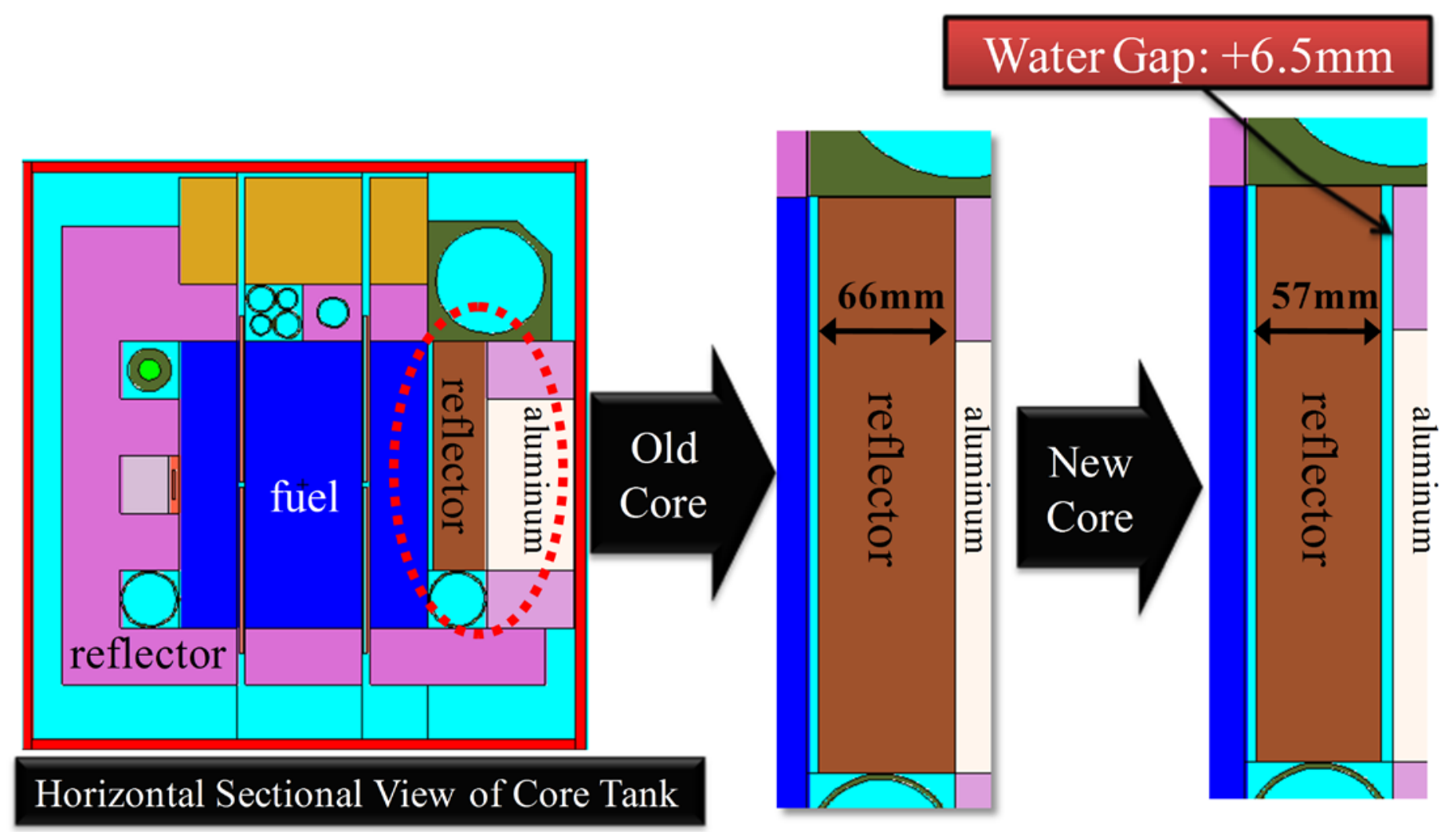


Figure 2 Vertical sectional view of the JRR-4 Neutron Beam Facility

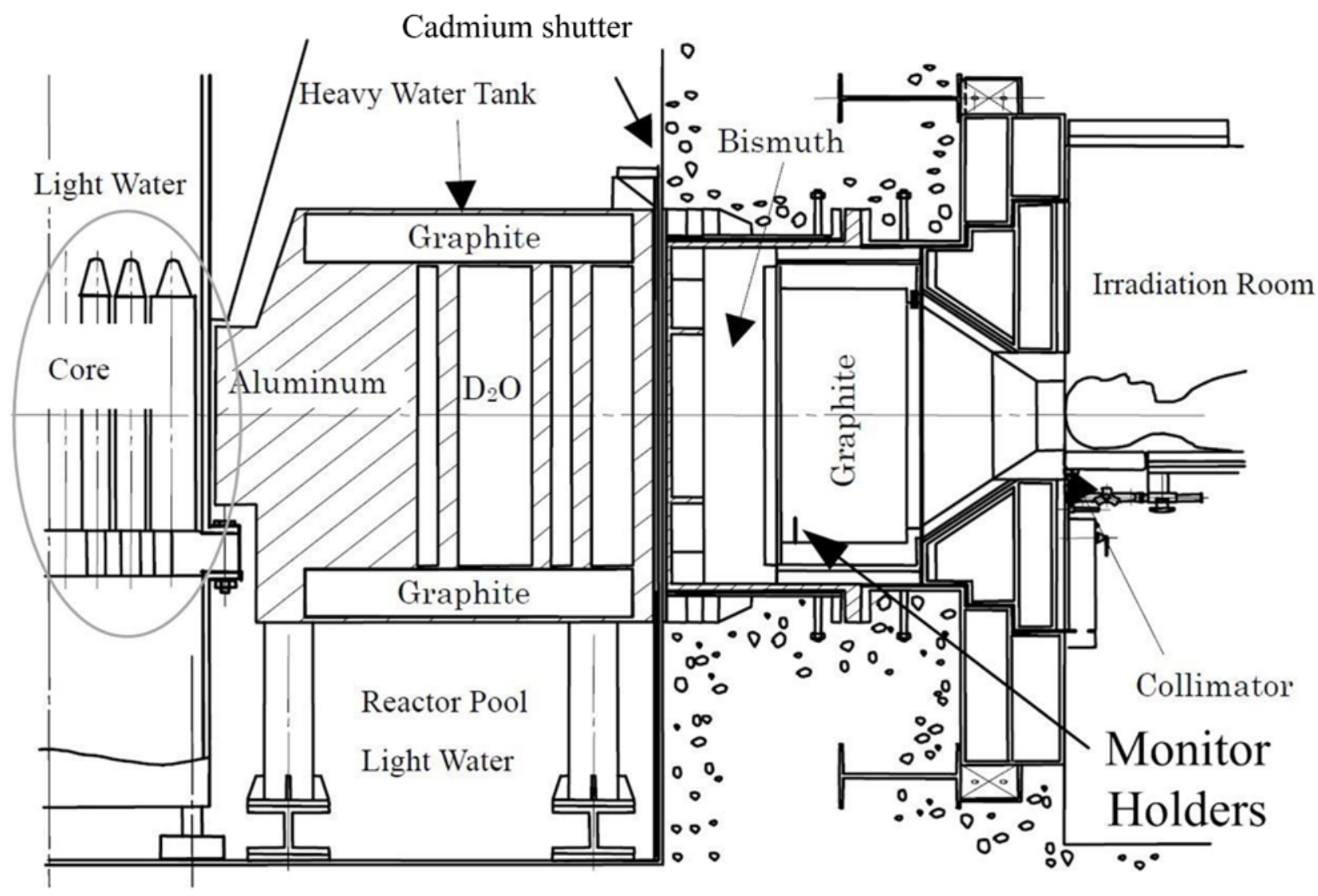


Figure 3 Thermal neutron flux distribution in the phantom in the ENB and TNB-1 modes

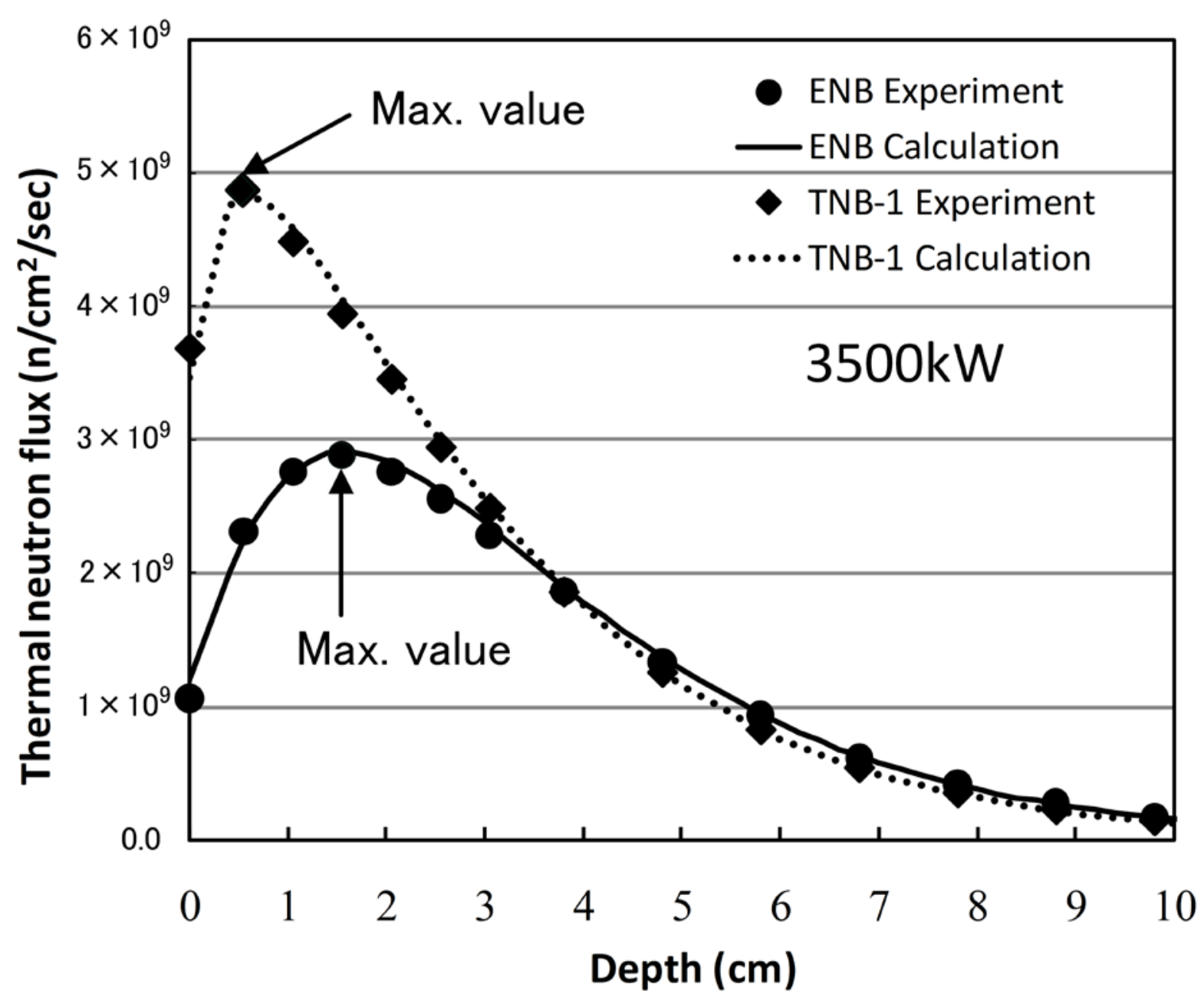


Figure 4 Gamma dose rate distribution in the phantom in the ENB, TNB-1 and TNB-2 modes

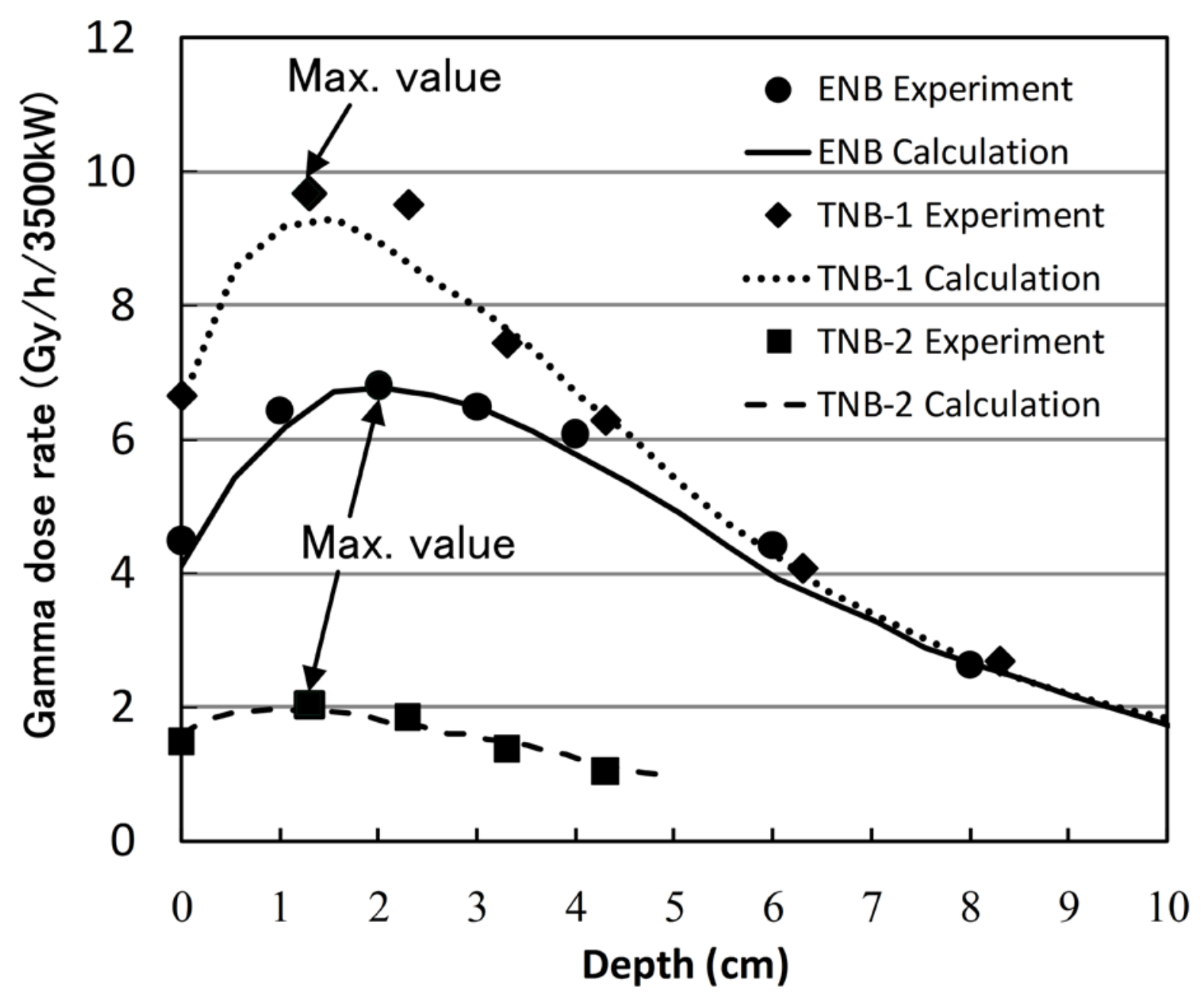


Figure 5 (a) Calculated neutron spectra by free air condition at aperture of collimator.(b) Ratio of new reflector/old reflector of calculated neutron spectra
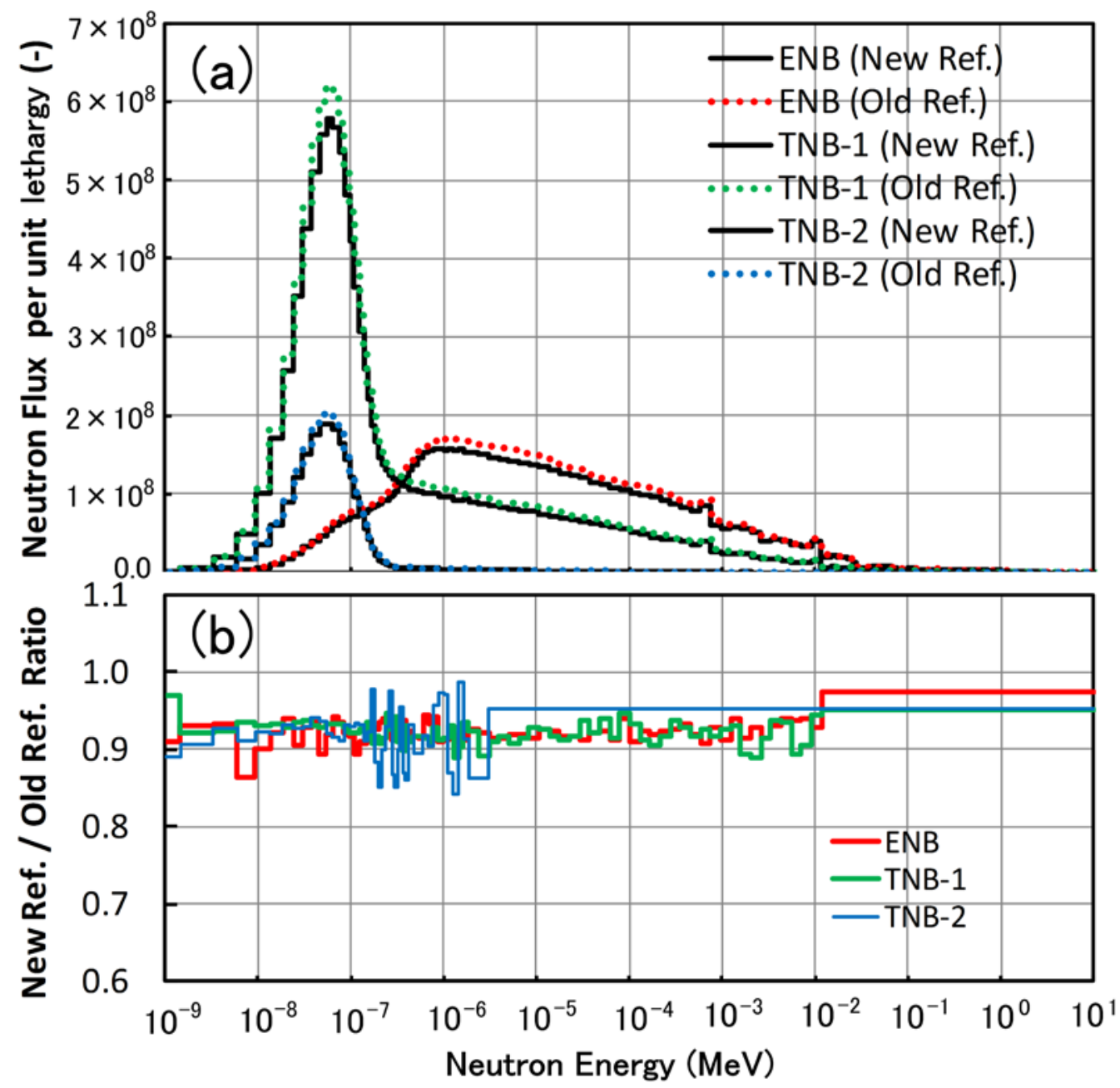